\title{
Small fiber neuropathy and related factors in patients with systemic lupus erythematosus; the results of cutaneous silent period and skin biopsy
}

\author{
Aslan Tekatas ${ }^{1}$, Demet Deniz Tekatas ${ }^{2}$, Volkan Solmaz $^{3^{*}}$, , Turan Karaca ${ }^{4}$ and Omer Nuri Pamuk ${ }^{5}$
}

\begin{abstract}
Introduction: Evaluating small nerve fibers in patients with systemic lupus erythematosus (SLE) using cutaneous silent period (CSP) and skin biopsy and assesssing the relationship between clinical signs, autoantibodies and neuropathic pain score.

Objective - methods: Fifty one SLE patients and 46 healthy volunteers were included in this study. Nerve conduction studies and CSP were performed both on upper and lower limbs in subjects. Skin biopsy was performed and the number of epidermal nerve density and IL-6 staining were evaluated.

Results: In SLE patients, CSP latencies were significantly prolonged both in lower and upper limbs and lower and upper extremity CSP durations were significantly shorter when compared to controls $(p<0.001)$. The number of epidermal nerve was significantly lower in SLE patients when compared to healthy controls $(p<0.001)$.
\end{abstract}

Conclusion: We detected marked small nerve fiber damage in both lower and upper limbs in SLE patients using CSP. Decreased epidermal nerve density also supports this finding.

Keywords: Systemic lupus erythematosus, Cutaneous silent period, Small fiber neuropathy, Epidermal nerve density, Electromyography

\section{Introduction}

Systemic lupus erythematosus (SLE) is chronic inflammatory autoimmune disease affecting many organs, characterized by autoantibody and immune complex production against nuclear antibodies [1]. There have been many studies evaluating clinical findings and possible mechanisms about central nervous system (CNS) involvement in SLE patients. Peripheral nervous system (PNS) involvement, having an important potential effect on quality of life of the patients, has not drawn attention as much [2].

Frequency of peripheral neuropathy in SLE patients has been reported as $10-20 \%$ varying in different studies

\footnotetext{
* Correspondence: solmaz.volkan85@gmail.com

${ }^{3}$ Department of Neurology, Memorial Hizmet hospital, 34100 istanbul, Turkey Full list of author information is available at the end of the article
}

$[2,3]$. Some SLE patients suffer neuropathic symptoms suchs as pain, numbness and burning feeling more when compared to healthy volunteers, but they do not have any neurologic involvement signs corresponding to these symptoms. Thus, some authors consider this situation as a secondary involvement of small fiber neuropathy (SFN) [4]. In addition, it is known that some sensorial and sensorimotor polyneuropathies starts with the involvement of small fiber and then the large fibers are affected [5].

Small fiber neuropathy is a peripheral nerve disorder affecting specifically small myelinated A delta fibers and unmyelinated $C$ fibers [6]. It is one of the common causes of neuropathic pain syndrome, however it can not be shown in conventional nerve conduction studies (NCS) and this makes it difficult to diagnose [7]. Until

(c) The Author(s). 2020 Open Access This article is licensed under a Creative Commons Attribution 4.0 International License, which permits use, sharing, adaptation, distribution and reproduction in any medium or format, as long as you give appropriate credit to the original author(s) and the source, provide a link to the Creative Commons licence, and indicate if changes were made. The images or other third party material in this article are included in the article's Creative Commons licence, unless indicated otherwise in a credit line to the material. If material is not included in the article's Creative Commons licence and your intended use is not permitted by statutory regulation or exceeds the permitted use, you will need to obtain permission directly from the copyright holder. To view a copy of this licence, visit http://creativecommons.org/licenses/by/4.0/. 
now, there is not a gold standard method for diagnosing SFN. Diagnosis is made with the use of temperature perception, sudomotor and cardiovagal tests accompanied by clinical findings and evaluating the epidermal nerve fiber density with a biopsy [8]. Biopsy is not a clinically practical approach as it is an invasive method and can not be performed and evaluated in every center.

It was reported that cutaneous silent period (CSP) can be used as an objective method for evaluating small nerve fibers [9]. CSP is not certain as a measurement for SFN, however, many studies performed on patients with SFN such as diabetes mellitus, restless leg syndrome, HIV neuropathy, hereditary sensory autonomic neuropathies, and showed abnormal findings in CSP measurements [10-12]. The physiologic mechanisms causing the CSP remain uncertain. However, many researchers agree that it is a spinal inhibitory reflex $[13,14]$. The suggested mechanism of CSP is stimuli reaching medulla spinalis by A delta fibers via dorsal root and a postsynaptic inhibition by spinal interneurons and motor neurons. This inhibition is controlled with supraspinal efferent pathways from motor cortex [15].

For a long time, it is known that there are symptoms that lead us to consider SFN in SLE patients and also it is has been demonstrated histopathologically $[16,17]$. Also, it was detected in a recent study that SFN may be an unrecognized cause of morbidity and SLE patients [18]. We have not come across any study evaluating SFN in SLE patients using CSP in literature.

In this study, our aim was to investigate if there is small nerve fibers involvement in patients with SLE by using CSP. In addition, the effect of clinical signs such as involvement of organs, presence of specific autoantibodies, and neuropathic pain score on CSP will be evaluated. Also, skin biopsy was performed in a group of SLE patients and the relationship between CSP and epidermal nerve fiber density was investigated.

\section{Patients and methods \\ Study population}

Patients diagnosed with SLE and a control group of healthy individuals were assigned to this study. For this purpose, 51 patients treated for SLE in Trakya University Faculty of Medicine Rheumatology Clinic and 46 healthy volunteers who are at the same age and same sex of these patients were included in the study.

The modified 1997 American College of Rheumatology criteria was used for the classification of SLE [19, 20]. Patients who fulfilled at least 4 criteria were diagnosed with SLE. The medical charts of the patients were thoroughly investigated for diagnostic criteria and other clinical features in a retrospective manner.

The history of a illness which might affect the CNS and PNS (SLE patients with CNS involvement before, except), chronic alcohol abuse history (according to DSM-V criteria), presence of diabetes mellitus, coexistence of other rheumatic diseases, thyroid dysfunction, chronic renal failure, vitamin B12 and folic acid deficiency, history of cerebral infarction and usage of chemotherapy, antiepileptic drugs, methotrexate, colchicine, talidomide and others drugs that can cause pheripheral neuropathy were considered as exclusion criteria. The study protocol was approved by our local ethical committee (TÜTF-BAEK 2015/102). All patients were informed about study design and gave written consent to take part in the study.

All patients' physical examinations were performed. Their demographic and clinical characteristics were obtained from hospital records. A detailed medical history was taken from each patient and neurological examinations were performed before the NCS. At the time of initial diagnosis and at each visit, the patients were questionned for the presence of connective tissue disease related symptoms like joint symptoms, Raynaud's phenomenon, oral ulcers, dry eyes, dry mouth, skin rashes particularly after exposure to sunlight, and thrombotic events. The SLE disease activity index (SLEDAI) score, obtained from hospital records, were calculated for each patient. Patients with SLEDAI scores 6 or higher at the time of initial diagnosis were taken as a separate group.

Antinuclear antibody (ANA), anti-ds-DNA and extractable nuclear antigen (ENA) antibodies results of SLE patients, which were taken previously during the diagnosis period, were obtained from medical charts. ANA was determined with indirect immunofluorescent method. Titers at or above 1/100 were accepted to be positive. Anti-dsDNA was determined by the Crithidia lucilia method [21]. ENA (Anti-Ro, anti-La, Anti-Sm, anti-RNP, and anti-Scl70) were determined by immunoblotting. All ANA tests were evaluated in the same laboratory with same method by the same laboratory technician.

\section{Electrophysiologic tests}

NCS and CSP evaluation were performed in our electrophysiology laboratory at Trakya University Department of Neurology. Electrophysiologic studies were made using 4channel Medelec Synergy device. Tests were performed in a semi-darkened, quiet room having a temperature of 25 C. Recordings were made $3 \mathrm{~h}$ after the lunch when the patient had empty bowels and an empty bladder. Electrophysiological tests were carried out by only one clinician blinded to the prior diagnose of participants.

\section{Nerve conduction study}

Oh's methods were utilized for nerve conduction studies [22]. In addition to median and ulnar sensory and motor nerve conductions in upper limbs, peroneal, posterior tibial motor nerve conduction and sural sensory nerve 
conduction velocity (meter/second) in lower limbs, amplitude (mili and microvolt) and distal latency (millisecond) parameters were measured. For the motor nerve conduction, lower limit was adjusted to $2-20 \mathrm{~Hz}$, and upper limit to $10 \mathrm{kHz}$. Ten milivolt and 50 milisecond values were used for amplitude and sweep rate respectively. Stimulation intensity was continued until the amplitude of the response is stable. Selected lower frequency limit was in the $5-20 \mathrm{~Hz}$ range and upper frequency limit was in the $2-3 \mathrm{kHz}$ range during the sensory NCS. Two hundred microvolts for amplitude and 20 milisecond for sweep were preferred.

The values obtained were compared with normal reference values our electrophysiology laboratory. Those having NCS parameter abnormality for at least two different nerves were considered as polyneuropathy.

\section{Cutaneous silent period}

CSP measurements were performed on both upper and lower limbs according to $\mathrm{Oz}$ et al. [23]. Firstly, patients' pain thresholds were determined. To evaluate pain threshold of the patients, a gradually increasing electrical stimulaton was given to lateral malleolus in lower extremity and index finger in upper extremity, starting with $0.2 \mathrm{~ms}$ duration and $0.6 \mathrm{~mA}$. The point where the patients started to feel the pain was defined as pain threshold. CSP measurements were performed on right side abductor pollicis brevis (APB) muscle in upper extremity and right-side anterior tibialis (AT) muscle in lower extremity. An electrical stimulation of 15 times the pain threshold was given to right hand index finger through ring electrode in the upper extremity. At the same time, patient was asked to abduct their right thumb. Recordings were made using a bar electrode from the right-side APB muscle when the patient performed a voluntary contraction with an amplitude of $75 \%$ of the maximal motor unit potential (MUP). For the right leg, recordings were made using a bar electrode from the right-side lateral malleolus when the patient performed a contraction in AT muscle with an amplitude of $75 \%$ of the maximal MUP after the nerve stimulation. An inhibited period followed the MUPs gathered during the submaximal contraction. This period, which is called CSP, was shown on screen. Starting and ending latencies of the CSP duration were measured and it was calculated as CSP duration. CSP was measured 10 times consecutively for each extremity and longest and shortest latency values were used.

Age and sex matched control group was used for comparison and CSP values \pm 2 standard deviation different from those in the control group were considered as pathological.

\section{Neuropathic pain assessment}

In order to the diagnosis of neuropathic pain the Leeds Assessment of Neuropathic Symptoms and Signs
(LANSS) pain scale was used [24]. This scale consists of 5 neuropathic sensory disturbance domains complemented by 2 sensory examination items. We did not use the sensorial part of this scale. The validation and reliability of the Turkish version of the LANSS scale was accomplished [25].

\section{Skin biopsy for epidermal nerve fiber density}

Punched skin biopsy was performed, with a circular blade in size $4 \mathrm{~mm}$ one times, in consecutive 12 SLE and 10 control subjects before electrophysiologic NCS. Skin biopsy was applied in medial malleoli. Biopsy samples were embedded paraffin sections and were cut by $0.5 \mu \mathrm{m}$ slides. For immunohistochemistry, paraffine slides were deparaffinized in toluen and rehydrated in a series of graded alcohols, and the antigen was retrieved in $0.01 \mathrm{~mol} / \mathrm{L}$ sodium citrate buffer. Sections were then treated with $3 \%$ of hydrogen peroxide to inhibit endogenous peroxidase. To prevent non-specific binding of antibodies, they were incubated in blocking serum (Thermo Scientific/Lab Vision) for $5 \mathrm{~min}$ at room temperature. PGP 9.5 (1:200; Novus, NB100-65827) and IL-6 (1:400; Novus, NB600-1131) stainings were made by immunohistochemically [26, 27]. 3-amino-9-ethyl-carbazole (AEC, Substrate System, Thermo Scientific/Lab Vision) was used as a chromogene. Counterstaining was completed with hematoxylin (Sigma, Germany). Epidermal nerve fiber density was detected in every $\mathrm{mm}^{2}$. In addition, IL-6 staining density was detected and scored according to previous literature [27]. Tissue sections were assessed under a light microscope at magnification (400X, Olympus CX31, Japan).

\section{Statistical analysis}

SPSS 15.0 for Windows (SPSS Inc. Chicago, IL, USA) was used for statistical analysis. Chi-square test was used for comparing of categorical datas between groups and unpaired t-test for comparing continious variables as they had a normal distribution. Correlation analysis was made using Pearson test.

\section{Results}

Fifty-one SLE (48 female, 3 males, mean age: $39.96 \pm$ 9.4), and 46 healthy control subjects (42 females, 4 males, mean age: $40 \pm 9.2$ ) were included the study. The distribution of sex and mean age of groups were similar $(p>0.05)$. The clinical features of SLE patients were shown in Table 1.

The mean level of upper and lower extremity latencies were significantly higher in patients with SLE than in healthy control subjects $(p<0.001)$. In addition, the mean duration of upper and lower extremity were significantly shorter in SLE patients than in controls $(p<$ $0.001)$. The mean value of latencies and durations were seen in Table 2. The mean upper latency is significantly higher in active SLE patients (SLEDAI score $\geq 6$ ) when 
Table 1 Clinical and laboratory characteristics of patients with SLE

\begin{tabular}{ll}
\hline $\mathrm{n}$ (F/M) & $48 / 3$ \\
\hline Disease duration (months) & $72.9 \pm 6.3$ \\
Arthritis, n (\%) & $36(70.5)$ \\
Photosensitivity, n (\%) & $28(54.9)$ \\
Raynaud's phenomenon, n (\%) & $12(23.5)$ \\
Discoid lupus, n (\%) & $7(13,7)$ \\
Oral ulcers, n (\%) & $15(29.4)$ \\
Serositis, n (\%) & $6(11.7)$ \\
CNS involvement, n (\%) & $6(11.7)$ \\
Renal involvement, n (\%) & $13(25.4)$ \\
Thrombosis, n (\%) & $6(11.7)$ \\
Autoimmune hemolytic anemia, n (\%) & $5(9.8)$ \\
Thrombocytopenia, n (\%) & $6(11.7)$ \\
Hypocomplementemia, n (\%) & $22(43.1)$ \\
SLEDAl score (mean \pm SD) & $4.3 \pm 3.4$ \\
SLEDAl score > 6 & 16
\end{tabular}

F Female, M Male, CNS Central nervous system, SLEDAI Systemic lupus erythematosus disease activity index, SD Standard deviation

compared to inactive patients $(85.41 \pm 4.9$ vs. $78.6 \pm 8.4$, $p=0.023)$. The mean level of upper latency of active SLE patients tended to be higher $(117.3 \pm 22$ vs. $108.3 \pm 13.9$, $p=0.08)$.

There were 13 patientes with Lupus nephritis (LN), and according to the 2003 International Society of Nephrology (ISN)/Renal Pathology Society (RPS) Classification criterias [28], 6 of them were Class I (Minimal mesangial LN), 4 of them were Class II (Mesangial proliferative LN) and 3 of them were Class III (Focal LN). LN was diagnosed with renal biopsy. Glomerular filtration rates (GFR) were significantly high in $\mathrm{LN}$ positive (GFR: $78,6 \pm 11,4 \mathrm{~mL} / \mathrm{min} / 1.73 \mathrm{~m}^{2}$ ) patients than $\mathrm{LN}$ negative patients (GFR: $99,7 \pm 13,8 \mathrm{~mL} / \mathrm{min} / 1.73 \mathrm{~m}^{2}$ ) $(p=0.034)$. In SLE patients with nephritis, the mean level of lower extremity latency was significantly higher than in SLE patients without nephritis $(119.4 \pm 20.2$ vs. $107.6 \pm 14.3, p=0.028$ ). Other EMG measures (NCS) were similar in patients with and without nephritis (all $p$ values >0.05). All the nerve conduction studies were similar in patients with and without anti-dsDNA (all $p$ values $>0.05$ ).

Table 2 Cutaneous silent period values of SLE patients and control group

\begin{tabular}{llll}
\hline & SLE & Control & $\mathrm{p}$ \\
\hline $\begin{array}{l}\text { Upper extremity } \\
\text { duration (ms) }\end{array}$ & $33.81 \pm 8.03$ & $47.44 \pm 7.51$ & $<0.001$ \\
$\begin{array}{l}\text { Lower extremity } \\
\text { latency (ms) }\end{array}$ & $111.14 \pm 17.14$ & $92.72 \pm 13.76$ & $<0.001$ \\
$\begin{array}{l}\text { Lower extremity } \\
\text { duration (ms) }\end{array}$ & $30.90 \pm 8.88$ & $49.44 \pm 8.39$ & $<0.001$ \\
\hline
\end{tabular}

Peripheral neuropathy was detected in 9 (17.6\%) patients of the SLE. There was no significant difference between SLE patients with and without peripheral neuropathy in their CSP values $(p>0.05)$. When we exclude SLE patients with prominent peripheral neuropathy, we detected that the mean duration of upper extremity was significantly lower in anti-dsDNA positive group than in anti-dsDNA negative group (30.2 \pm 7.3 vs. $35.5 \pm 7.3, p=0.029$ ).

The mean level of latency and duration were similar in SLE patients with and without hypocomplementemia, arthritis, photosensitivity, serositis, CNS involvement and other ENA antibodies. Age, treatment with antimalarials, steroids, immunsuppressives (azathioprine, cyclophosphamide), and hemogram parameters had no effect on the NCS or CSP results. Also, LANNS score was not associated with any clinical parameters and NCS or CSP measure.

In SLE patients, SLEDAI scores correlated with upper $(\mathrm{r}=0.36, p=0.009)$ and lower extremity latency $(\mathrm{r}=-$ $0.38, p=0.008)$. The level of lower extremity latency also correlated with ESR $(\mathrm{r}=0.34, p=0.01)$ and disease duration $(\mathrm{r}=0.30, p=0.03)$.

Epidermal nerve count and IL-6 staining density were measured in skin biopsy samples. In SLE patients, the mean number of epidermal nerves was significantly lower and the severity of IL-6 was significantly higher when compared to healthy control subjects ( $p$ values < 0.001) (Figs. 1 and 2).

\section{Discussion}

In our study, prolonged latency values were detected in lower and upper limbs in CSP evaluations, whereas we found a significant shortening of the CSP duration. These results might support the common presence of SFN in SLE. To our knowledge, there is no study so far that is demonstrating SFN in SLE with the use of CSP. Peripheral neuropathy is a known clinical entity in SLE and it is described under the title of neurologic involvement in new SLICC criteria [29]. There was no correlation between CSP evaluation values and neuropathic pain scores assessed by LANNS. However, early or subclinical signs of neuropathy in SLE might be associated with significantly affected CSP values.

Skin biopsy can be reliable for showing the loss in the intraepidermal nerve fibers when clinical and neurophysiological studies are not satisfactory [30, 31]. Skin biopsy is an easy to perform, highly sensitive, a minimally invasive method. However, it is not practical as it needs complex histologic techniques, special equipment and expertise. In our study, we detected that epidermal nerve fiber density significantly decreased in SLE patients when compared with the controls. Omdal et al. [16] reported a significant decrease in epidermal nerve 


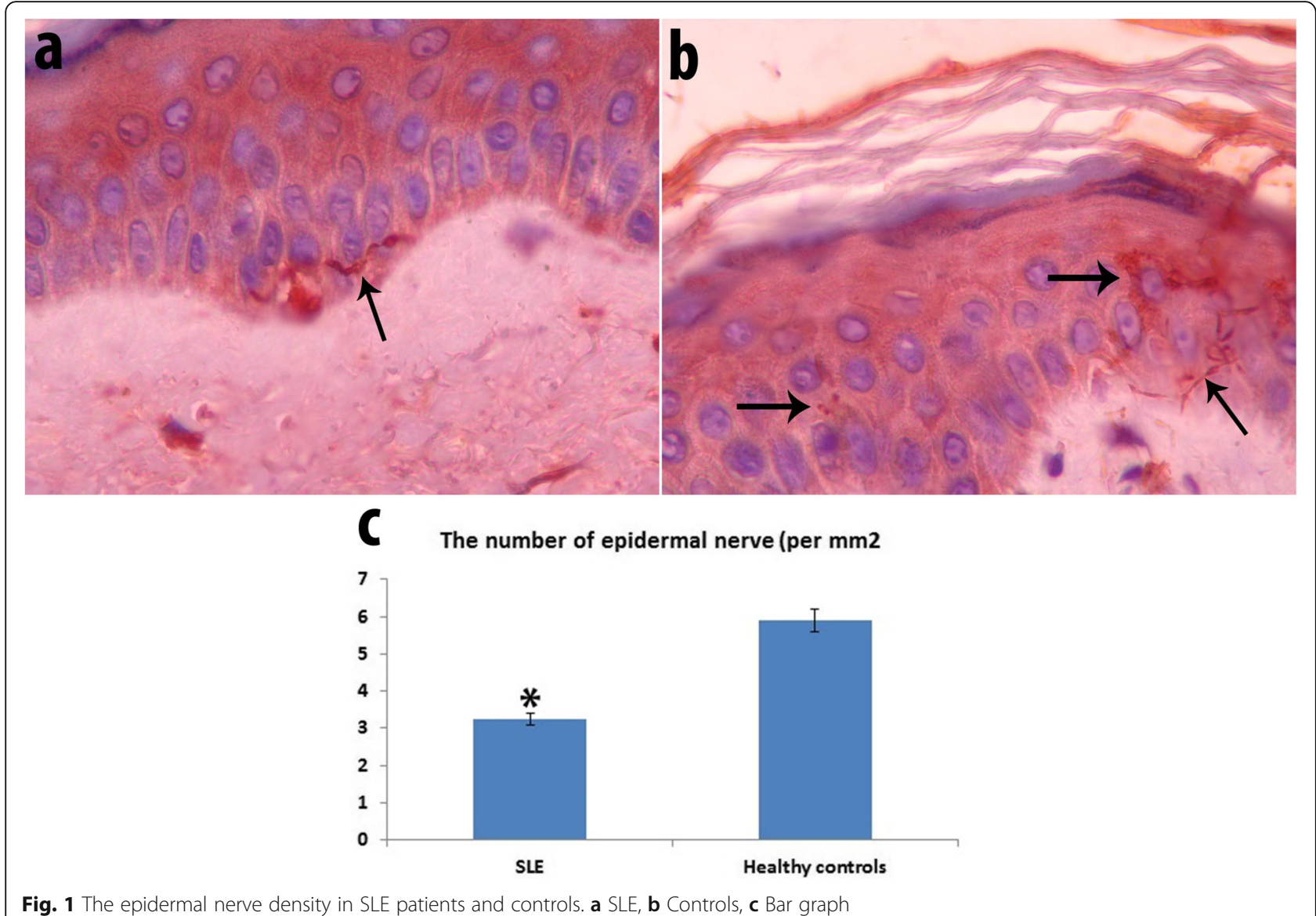

fiber density in SLE patients similar to our study. Tseng et al. [17] reported that the frequency of intraepidermal skin denervation (82.2\%) was significantly more frequent in SLE patients than abnormal quantitative sensory test (33.3\%) and abnormal NCS (31\%). This study reveals the insufficiency of the electrophysiological methods. In that study, a decreased intraepidermal nerve fiber (IENF) density was detected in patients with active SLE compared to the ones who have inactive SLE. It has been suggested that small fiber involvement was affected by the disease activity. However, a decreased IENF density was also detected in patients with inactive SLE compared to control group. In our study, the relationship between SLEDAI score and the latency of the upper limb, suggest that CSP is affected by the disease activity. However, we could not find a relationship between CSP and indicator of the disease activity including C3 level. Already, conflicting results have been obtained from studies conducted based on hypocomplementemia [32-34].

Relevant studies suggested that there is no relationship between increased SFN and clinical manifestation and presence of autoantibodies along with disease activity in SLE [32]. Factors such as age, duration of disease, ENA results, hypocomplementemia, hematologic or specific organ involvement and arthritis had no effect on SFN results in our study.

However, renal involvement was related to SFN in our study. Acoordingly, in SLE patients with nephritis, the mean level of lower extremity latency was significantly higher than in SLE patients without nephritis, GFR levels are also lower in the LN positive group. Prolonged CSP duration and latencies may be related to SLE itself or to low GFR in this group. However, our analysis showed that CSP latency and duration of LN negative patients were also longer than the controls, therefore, we think that this is directly related to SLE rather than renal involvement in SLE. Patients with renal involvement were not in the last stage of renal failure. This situation might be associated with the SFN due to increased disease activity or advanced stage of the disease.

Peripheral neuropathy was detected in 9 of the patients using NCS. Consistent with our study, in a study of SLE patients, Goransson et al. [32] performed skin biopsy, NCS and neurologic examination for detecting peripheral neuropathy. Abnormal NCS results were detected in 11 cases (18\%) and they were reported as major nerve damage. Of these, a decrease in IENF density was 


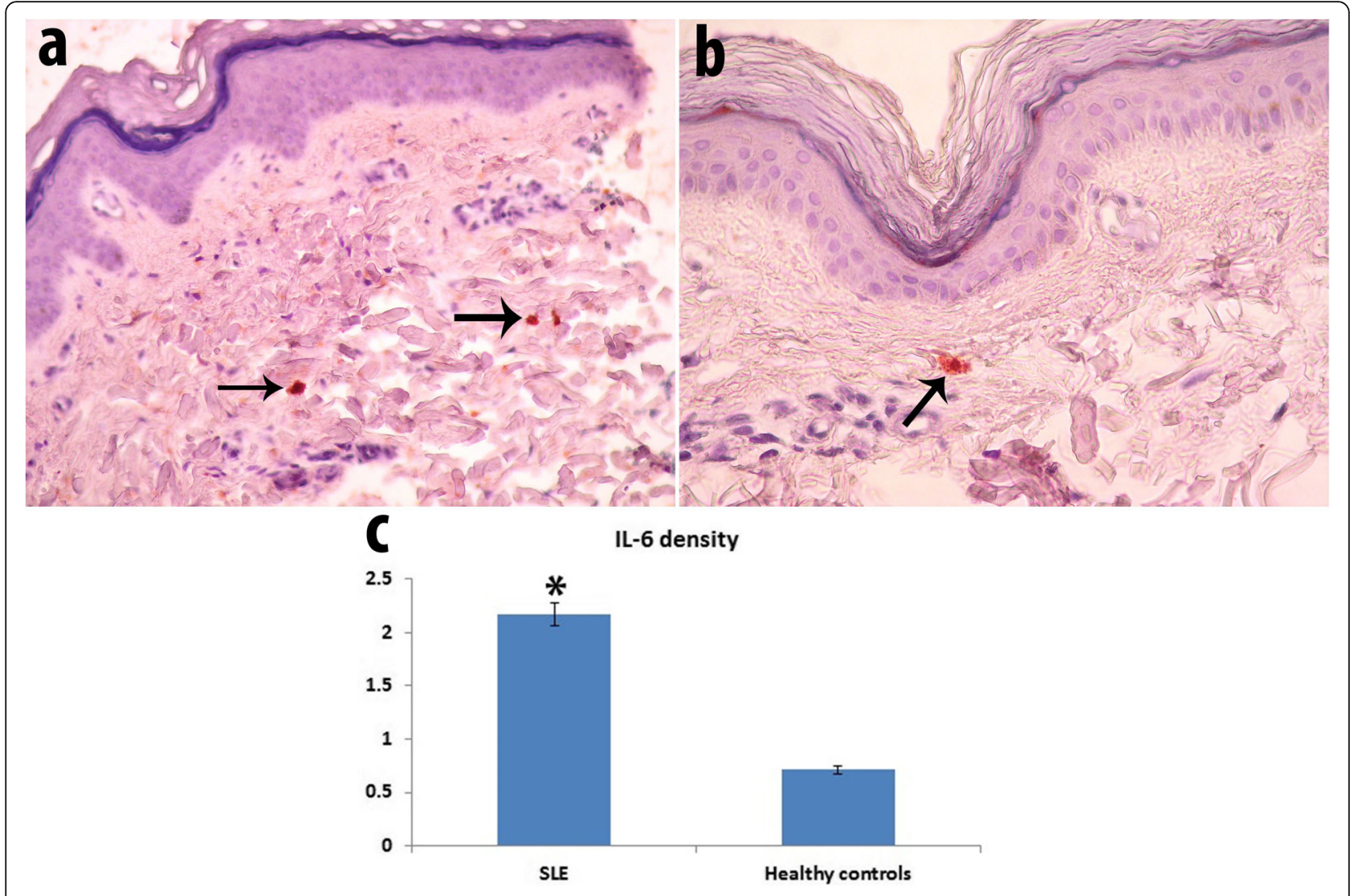

Fig. 2 IL-6 density in SLE patients and controls. a SLE, b Controls, c Bar graph

detected in only 2 patients, and signs of peripheral neuropathy were reported in 3 patients. A decrease in IENF density was alone detected in the remaining 6 patients. About this result, researchers concluded that small and large fiber neuropathy in SLE might be associated with different pathophysiologic mechanisms. Nerve denervation in SLE patients has been reported to be present not only in patients with peripheral neuropathy and also in those with CNS involvement as well [32]. In our study we could not find an association between CNS involvement and CSP. Furthermore, the association between CNS and PNS involvement and different mechanisms might be another factor.

Although the pathophysiological process leading to SFN is uncertain, it is thought to be directly or indirectly immune mediated [33, 34]. Vasa nervorum and epineural arteries might be affected in systemic vasculitis, causing nerve degeneration $[35,36]$. In addition to this, some researchers stated that small nerve fibers might be more sensitive to vasculitis and neuropathy than large fibers. Moreover, it is proposed that antibodies only reacting with small fibers occur due to a nonspecific activation of $\mathrm{B}$ cells or a general immune activation associated with other factors in some of the SLE patients $[37,38]$. However, except for anti-dsDNA, there was no correlation between autoantibodies and SFN or NCS in our study.

In our study, we detected an abnormal finding in SLE patients using a noninvasive method which can be carried out in a simple electrophysiology laboratory and relatively invasive skin biopsy. Consequently, longitudinal studies are needed to determine what the outcome of SFN would be in the long term.

\section{Conclusion}

In conclusion, we found a striking SFN in patients with SLE using CSP in our study. Despite similar findings in the previous studies, it is important that we detected SFN at a simple electrophysiology laboratory and with the use of a noninvasive method. Nephritis and presence of anti-dsDNA in a specific subgroup were signs found to be associated with SFN. Decreased epidermal nerve density in skin biopsy also supports the increased SFN in SLE patients. However, what this finding means in the long term must be assessed, because the association with neuropathic pain score could not be shown.

Acknowledgements

None. 


\section{Financial support}

There is no financial support in our study.

\section{Ethical approval}

We declare that all procedures performed in studies involving human participants were in accordance with the ethical standards of the institutional and/or national research committee and with the 1964 Helsink declaration and its later amendments or comparable ethical standards.

\section{Authors' contributions}

AT: study design and electrophysiological study, DDT: data collecting manuscript writing, VS: electrophysiological studies and data collecting, TK: histopathological evaluating, ÖNP: Manuscript writing and study design. The author(s) read and approved the final manuscript.

\section{Funding}

There is no funding sources in this study.

\section{Availability of data and materials}

All relevant raw data, will be freely available to any scientist wishing to use them for non-commercial purposes, without breaching participant confidentiality.

\section{Ethics approval and consent to participate}

This study performed in accordance with the Declaration of Helsinki and the local ethic comitee confirmed our study (TÜTF-BAEK 2015/102) and all the participants signed the informed consent form.

\section{Consent for publication}

Written informed consent for the publication of the datas and deteals relating to the participants has been obtained from the participants.

\section{Competing interests}

All the authors declare that there are no financial or non-financial competing interests.

\section{Author details}

'Department of Neurology, Medikent Hospital, Kirklareli, Turkey. ${ }^{2}$ Department of Internal Medicine, Medikent Hospital, Krrklareli, Turkey. ${ }^{3}$ Department of Neurology, Memorial Hizmet hospital, 34100 Istanbul, Turkey. ${ }^{4}$ Department of Histology, Trakya University Medical Faculty, Edirne, Turkey. ${ }^{5}$ Department of Internal Medicine, Division of Rheumatology, Trakya University Medical Faculty, Edirne, Turkey.

Received: 25 January 2020 Accepted: 27 May 2020

Published online: 05 June 2020

\section{References}

1. Kyogoku C, Tsuchiya N. A compass that points to lupus: genetic studies on type I interferon pathway. Genes Immun. 2007;8(6):445-55. https://doi.org/ 10.1038/sj.gene.6364409.

2. Florica B, Aghdassi E, Su J, Gladman DD, Urowitz MB, Fortin PR. Peripheral neuropathy in patients with systemic lupus erythematosus. Semin Arthritis Rheum. 2011;41(2):203-11. https://doi.org/10.1016/j.semarthrit.2011.04.001.

3. Harboe E, Tjensvoll AB, Maroni S, Goransson LG, Greve OJ, Beyer MK, et al. Neuropsychiatric syndromes in patients with systemic lupus erythematosus and primary Sjogren syndrome: a comparative population-based study. Ann Rheum Dis. 2009;68(10):1541-6. https://doi.org/10.1136/ard.2008.098301.

4. Omdal R, Mellgren Sl, Husby G, Salvesen R, Henriksen OA, Torbergsen T. A controlled study of peripheral neuropathy in systemic lupus erythematosus. Acta Neurol Scand. 1993;88(1):41-6.

5. Lacomis D. Small-fiber neuropathy. Muscle Nerve. 2002;26(2):173-88. https:// doi.org/10.1002/mus.10181.

6. Tavee J, Zhou L. Small fiber neuropathy: a burning problem. Cleve Clin J Med. 2009;76(5):297-305. https://doi.org/10.3949/ccjm.76a.08070.

7. Devigili G, Tugnoli V, Penza P, Camozzi F, Lombardi R, Melli G, et al. The diagnostic criteria for small fibre neuropathy: from symptoms to neuropathology. Brain. 2008;131(Pt 7):1912-25. https://doi.org/10.1093/ brain/awn093.

8. Bakkers M, Merkies IS, Lauria G, Devigili G, Penza P, Lombardi R, et al. Intraepidermal nerve fiber density and its application in sarcoidosis.
Neurology. 2009;73(14):1142-8. https://doi.org/10.1212/WNL. 0b013e3181bacf05.

9. Syed NA, Sandbrink F, Luciano CA, Altarescu G, Weibel T, Schiffmann R, et al. Cutaneous silent periods in patients with Fabry disease. Muscle Nerve. 2000;23(8):1179-86.

10. Osio M, Zampini L, Muscia F, Valsecchi L, Comi C, Cargnel A, et al. Cutaneous silent period in human immunodeficiency virus-related peripheral neuropathy. J Peripheral Nervous Syst. 2004;9(4):224-31. https:// doi.org/10.1111/j.1085-9489.2004.09400.x.

11. Corsi FM, Fausti S, Serrao M, Casali C, Parisi L, Piazza G. Electromyographic mixed nerve and cutaneous silent period in evaluating the A-delta fibres in a patient with hereditary sensory-autonomic neuropathy. Funct Neurol. 2002;17(1):31-4.

12. Kim BJ, Kim NH, Kim SG, Roh H, Park HR, Park MH, et al. Utility of the cutaneous silent period in patients with diabetes mellitus. J Neurol Sci. 2010;293(1-2):1-5. https://doi.org/10.1016/j.jns.2010.03.032.

13. Uncini A, Kujirai T, Gluck B, Pullman S. Silent period induced by cutaneous stimulation. Electroencephalogr Clin Neurophysiol. 1991;81(5):344-52.

14. Inghilleri M, Cruccu G, Argenta M, Polidori L, Manfredi M. Silent period in upper limb muscles after noxious cutaneous stimulation in man. Electroencephalogr Clin Neurophysiol. 1997;105(2):109-15.

15. Floeter MK. Cutaneous silent periods. Muscle Nerve. 2003;28(4):391-401. https://doi.org/10.1002/mus.10447.

16. Omdal R, Mellgren SI, Goransson L, Skjesol A, Lindal S, Koldingsnes W, et al. Small nerve fiber involvement in systemic lupus erythematosus: a controlled study. Arthritis Rheum. 2002;46(5):1228-32. https://doi.org/10.1002/art.10303.

17. Tseng MT, Hsieh SC, Shun CT, Lee KL, Pan CL, Lin WM, et al. Skin denervation and cutaneous vasculitis in systemic lupus erythematosus. Brain. 2006;129(Pt 4):977-85. https://doi.org/10.1093/brain/awl010.

18. Oomatia A, Fang H, Petri M, Birnbaum J. Peripheral neuropathies in systemic lupus erythematosus: clinical features, disease associations, and immunologic characteristics evaluated over a twenty-five-year study period. Arthritis Rheum. 2014;66(4):1000-9. https://doi.org/10.1002/art.38302.

19. Tan EM, Cohen AS, Fries JF, Masi AT, McShane DJ, Rothfield NF, et al. The 1982 revised criteria for the classification of systemic lupus erythematosus. Arthritis Rheum. 1982;25(11):1271-7.

20. Hochberg MC. Updating the American College of Rheumatology revised criteria for the classification of systemic lupus erythematosus. Arthritis Rheum. 1997;40(9):1725. https://doi.org/10.1002/1529-0131(199709)40:9\&lt; 1725 AID-ART29\&gt:3.0.CO;2-Y.

21. Al-Shukaili A, Al-Jabri AA, Al-Moundhri MS. Prognostic value of autoantibodies in the serum of Omani patients with gastric cancer. Saudi Med J. 2006;27(12):1873-7.

22. SJ O. Clinical electromyograph: nerve conduction studies. Baltimore: University Park Press; 1993. p. 85-104.

23. Oz O, Erdogan C, Yucel M, Akgun H, Kutukcu Y, Gokcil Z, et al. Effect of pramipexole on cutaneous-silent-period parameters in patients with restless legs syndrome. Clin Neurophysiol. 2012;123(1):154-9. https://doi.org/10. 1016/j.clinph.2011.05.027.

24. Bennett M. The LANSS pain scale: the Leeds assessment of neuropathic symptoms and signs. Pain. 2001;92(1-2):147-57.

25. Yucel A, Senocak M, Kocasoy Orhan E, Cimen A, Ertas M. Results of the Leeds assessment of neuropathic symptoms and signs pain scale in Turkey: a validation study. J Pain. 2004;5(8):427-32. https://doi.org/10.1016/j.jpain.2004.07.001.

26. Yokobori S, Gajavelli S, Mondello S, Mo-Seaney J, Bramlett HM, Dietrich WD, et al. Neuroprotective effect of preoperatively induced mild hypothermia as determined by biomarkers and histopathological estimation in a rat subdural hematoma decompression model. J Neurosurg. 2013;118(2):37080. https://doi.org/10.3171/2012.10.JNS12725.

27. Cammarota R, Bertolini V, Pennesi G, Bucci EO, Gottardi O, Garlanda C, et al. The tumor microenvironment of colorectal cancer: stromal TLR-4 expression as a potential prognostic marker. J Transl Med. 2010;8:112. https://doi.org/ 10.1186/1479-5876-8-112.

28. Weening JJ, D'Agati VD, Schwartz MM, Seshan SV, Alpers CE, Appel GB, et al. The classification of glomerulonephritis in systemic lupus erythematosus revisited. Kidney Int. 2004;65(2):521-30. https://doi.org/10.1111/j.1523-1755. 2004.00443.x.

29. Petri M, Orbai AM, Alarcon GS, Gordon C, Merrill JT, Fortin PR, et al. Derivation and validation of the systemic lupus international collaborating clinics classification criteria for systemic lupus erythematosus. Arthritis Rheum. 2012;64(8):2677-86. https://doi.org/10.1002/art.34473. 
30. Lauria G, Cornblath DR, Johansson O, McArthur JC, Mellgren SI, Nolano M, et al. EFNS guidelines on the use of skin biopsy in the diagnosis of peripheral neuropathy. Eur J Neurol. 2005;12(10):747-58. https://doi.org/10 1111/j.1468-1331.2005.01260.x.

31. Gibbons CH, Griffin JW, Polydefkis M, Bonyhay I, Brown A, Hauer PE, et al. The utility of skin biopsy for prediction of progression in suspected small fiber neuropathy. Neurology. 2006;66(2):256-8. https://doi.org/10.1212/01. wnl.0000194314.86486.a2.

32. Goransson LG, Tjensvoll AB, Herigstad A, Mellgren SI, Omdal R. Smalldiameter nerve fiber neuropathy in systemic lupus erythematosus. Arch Neurol. 2006;63(3):401-4. https://doi.org/10.1001/archneur.63.3.401.

33. Griffin JW, Cornblath DR, Alexander E, Campbell J, Low PA, Bird S, et al. Ataxic sensory neuropathy and dorsal root ganglionitis associated with Sjogren's syndrome. Ann Neurol. 1990;27(3):304-15. https://doi.org/10.1002/ ana.410270313.

34. Kuntzer T, Antoine JC, Steck AJ. Clinical features and pathophysiological basis of sensory neuronopathies (ganglionopathies). Muscle Nerve. 2004; 30(3):255-68. https://doi.org/10.1002/mus.20100

35. Younger DS. Vasculitis of the nervous system. Curr Opin Neurol. 2004;17(3): 317-36.

36. Pagnoux C, Guillevin L. Peripheral neuropathy in systemic vasculitides. Curr Opin Rheumatol. 2005:17(1):41-8.

37. Dabby R, Weimer LH, Hays AP, Olarte M, Latov N. Antisulfatide antibodies in neuropathy: clinical and electrophysiologic correlates. Neurology. 2000;54(7): 1448-52.

38. Pestronk A, Choksi R, Logigian E, Al-Lozi MT. Sensory neuropathy with monoclonal IgM binding to a trisulfated heparin disaccharide. Muscle Nerve. 2003;27(2):188-95. https://doi.org/10.1002/mus.10301.

\section{Publisher's Note}

Springer Nature remains neutral with regard to jurisdictional claims in published maps and institutional affiliations.

Ready to submit your research? Choose BMC and benefit from:

- fast, convenient online submission

- thorough peer review by experienced researchers in your field

- rapid publication on acceptance

- support for research data, including large and complex data types

- gold Open Access which fosters wider collaboration and increased citations

- maximum visibility for your research: over $100 \mathrm{M}$ website views per year

At $\mathrm{BMC}$, research is always in progress.

Learn more biomedcentral.com/submissions 